\title{
The OMZ and nutrient features as a signature of interannual and low-frequency variability in the Peruvian upwelling system
}

\author{
Michelle I. Graco ${ }^{1}$, Sara Purca ${ }^{1}$, Boris Dewitte ${ }^{2,3,4}$, Carmen G. Castro ${ }^{5}$, Octavio Morón ${ }^{1}$, Jesús Ledesma ${ }^{1}$, \\ Georgina Flores ${ }^{1}$, and Dimitri Gutiérrez ${ }^{1}$ \\ ${ }^{1}$ Dirección General de Investigaciones Oceanográficas y cambio Climático, Instituto del Mar del Perú (IMARPE), \\ P.O. Box 22, Callao, Perú \\ ${ }^{2}$ Laboratoire d'Etudes en Géophysique et Océanographie Spatiale (LEGOS)/IRD, Toulouse, France \\ ${ }^{3}$ Universidad Católica del Norte, Facultad de Ciencias del Mar, Coquimbo, Chile \\ ${ }^{4}$ Centro de Estudios Avanzado en Zonas Áridas (CEAZA), Coquimbo, Chile \\ ${ }^{5}$ CSIC, Instituto de Investigaciones Marinas, Eduardo Cabello 6, 36208 Vigo, Spain
}

Correspondence to: Michelle I. Graco (mgraco@imarpe.gob.pe)

Received: 4 November 2015 - Discussion started: 15 January 2016

Revised: 27 April 2017 - Accepted: 29 August 2017 - Published: 19 October 2017

\begin{abstract}
Over the last decades, the Humboldt Current upwelling ecosystem, particularly the northern component off the coast of Peru, has drawn the interest of the scientific community because of its unique characteristics: it is the upwelling system with the biggest catch productivity despite the fact it is embedded in a shallow and intense oxygen minimum zone (OMZ). It is also an area of intense nitrogen loss and anammox activity and experiences large interannual variability associated with the equatorial remote forcing. In this context, we examined the oceanographic and biogeochemical variability associated with the OMZ off central Peru from a monthly time series (1996-2011) recorded off the coast of Callao $\left(12^{\circ} 02^{\prime} \mathrm{S}, 77^{\circ} 29^{\prime} \mathrm{W}\right)$. The data reveal a rich spectrum of variability in the $\mathrm{OMZ}$ that includes frequencies ranging from seasonal to interannual scales. Due to the efficient oceanic teleconnection off Peru, the observed variability is interpreted in the light of an estimate of the equatorial Kelvin wave contribution to sea level anomalies considering the peculiarities of its vertical structure (i.e., the first two baroclinic modes). The span of the data set allows us to contrast two OMZ regimes. The "strong" regime is associated with the strong 1997-1998 equatorial Pacific El Niño, during which the OMZ adjusted to Kelvin-wave-induced downwelling conditions that switched off the upwelling and drastically reduced nutrient availability. The "weak" regime corresponds to the post-2000 period associated with the occurrence of moderate central Pacific El Niño events and en-
\end{abstract}

hanced equatorial Kelvin wave activity, in which mean upwelling conditions are maintained. It is shown that the characteristics of the coupling between physics and biogeochemistry is distinct between the two regimes with the weak regime being associated with a larger explained variance in biogeochemical properties not linearly related to the ENSO oceanic teleconnection. The data also reveal a long-term trend from 1999 corresponding to a deepening of the oxygendeficient waters and warming. The implications of our results for understanding the OMZ dynamics off Peru are discussed.

\section{Introduction}

The upwelling region off Peru hosts a complex biogeochemical system that is unique for at least two reasons. First, it is embedded into the permanent, intense and shallow oxygen minimum zone (OMZ) of the eastern tropical South Pacific (Gutiérrez et al., 2008). Second, it exhibits significant variability at different timescales, particularly at the interannual scale associated with the equatorial Kelvin waves and the El Niño-Southern Oscillation (ENSO; Chavez et al., 2008).

The OMZ is generated by the combination of high oxygen demand during organic matter remineralization and the sluggish ventilation in the region (Wyrtki, 1962; Helly and Levin, 2004). It is wide in vertical extension $(\sim 500 \mathrm{~m})$ and intense $\left(<22.5 \mu \mathrm{mol} \mathrm{kg}^{-1}\right)$, and at some latitudes the upper 
boundary could be very shallow $(25-50 \mathrm{~m})$, intersecting the euphotic zone and impinging the continental shelf (Morales et al., 1999; Schneider et al., 2006; Fuenzalida et al., 2009; Paulmier and Ruiz-Pino, 2009; Ulloa and Pantoja, 2009). The OMZ off Peru is associated with the presence of nutrient-rich equatorial subsurface water (ESSW) transported poleward by the Peru-Chile Undercurrent (PCU; Strub et al., 1998; Fuenzalida et al., 2009; Silva et al., 2009) and the transport of low-oxygenated waters by the narrow primary and secondary Southern Subsurface Countercurrents near 4 and $7^{\circ} \mathrm{S}$, respectively, also known as Tsuchiya jets (Furue et al., 2007; Montes et al., 2010). Recent modeling studies also highlight the important role of submesoscale to mesoscale dynamics in constraining the upper OMZ meridional boundaries (Bettencourt et al., 2015; Vergara et al., 2016).

The OMZ variability in terms of distribution and intensity has a direct impact on the biogeochemical processes of the northern region of the Humboldt upwelling system because oxygen (1) is a key factor in biogeochemical cycles, particularly in the carbon (Friederich et al., 2008) and nitrogen processes (e.g., Kock et al., 2016; Hammersley et al., 2007; Lam and Kuypers, 2011; Dale et al., 2017). (2) Its consumption determines high nitrogen loss and in consequence a low $\mathrm{N}: \mathrm{P}$ ratio of upwelled waters, below the classical Redfield ratio of 16 , with a strong impact on primary and secondary production (Franz et al., 2012), and (3) it is a control factor in the distribution of organisms (e.g., Bertrand et al., 2010; Criales-Hernández et al., 2006; Ekau et al., 2010; Gutiérrez et al., 2008; Levin et al., 2002). The position, strength and thickness of the eastern South Pacific OMZ can be greatly modified by local and/or remote forcing (e.g., interannual timescales, Morales et al., 1999; Gutiérrez et al., 2008). During ENSO episodes, equatorial fluctuations in sea level and currents propagate along the Peruvian coast, which behaves as an extension of the equatorial waves guide (Clarke and van Gorder, 1994). Strong El Niño (EN) events, like the 19971998 eastern Pacific El Niño, affect circulation and water mass distribution, causing the deepening of the $\mathrm{OMZ}$ and the occurrence of large oxygenation events in the water column and over the sediments along the Chilean and Peruvian coast (Morales et al., 1999; Sánchez et al., 1999; Gutiérrez et al., 2008). In fact, Helly and Levin (2004) reported that during the 1997-1998 El Niño, about $61 \%$ of the OMZ volume off Peru and northern Chile was reduced.

While most studies on the interannual impact have focused on the 1997-1998 El Niño, recent studies indicate that the characteristics of the interannual variability have changed in the last decades. In fact, since the 90s a higher frequency of so-called central Pacific (or Modoki) El Niño events has occurred (Yeh et al., 2009; Lee and McPhaden, 2010; Takahashi et al., 2011). This type of El Niño event does not undergo a significant warming of sea surface temperature (SST) along the coast of Peru, in contrast to eastern Pacific El Niño events (Ashok et al., 2007; Dewitte et al., 2012). On the other hand, central Pacific El Niño events are associated with strong ac- tivity of intra-seasonal equatorial Kelvin waves (MosqueraVásquez et al., 2014) that can lead to thermocline depth fluctuations along the coast of Peru through the propagation of coastally trapped Kelvin waves (cTKW; Clarke, 1983; Dewitte et al., 2011; Illig et al., 2014).

The study of the relationship between ENSO and the OMZ would therefore require taking into account the different timescales of variability along the Equator, from intraseasonal to interannual. Most existing studies have documented the physical properties (Morón and Escudero, 1991; Morón, 2000) and chemical properties of the waters along the coast of Peru in relation to the interannual equatorial variability (Calienes and Guillén, 1981; Guillén and Izaguirre de Rondán, 1973; Guillén et al., 1989; Ledesma et al., 2011) disregarding the higher-frequency timescales and the diversity of ENSO (Capotondi et al., 2015). Here, we analyze a unique long-term time series of oxygen and inorganic nutrient data off central Peru, Callao, spanning 16 years (1996-2011). The region of Callao has been identified as one of the major upwelling cells off central Peru (Rojas de Mendiola, 1981) with a well-developed OMZ at the subsurface (Wooster and Gilmartin, 1961; Zuta and Guillén, 1970). The presence of nitrate-rich ESSW (Zuta and Guillén, 1970; Strub et al., 1998; Graco et al., 2007; Silva et al., 2009) triggers the high primary production of the region, with maximum values in spring and summer, out of phase with the winter upwelling maximum (Echevin et al., 2008; Chavez and Messié, 2009; Gutiérrez et al., 2011; Pennington et al., 2006; Vergara et al., 2016).

This data set offers the opportunity for insight into the ENSO oceanic teleconnection on the OMZ and nutrient features of the Peruvian upwelling system, considering recent advances in our understanding of ENSO events (Capotondi et al., 2015). The period under consideration encompasses characteristic events of the two ENSO regimes described by Takahashi et al. (2011): a strong eastern Pacific El Niño (i.e., the 1997-1998 strong El Niño) and a series of moderate central Pacific El Niño events after 2000. Finally, the study explores the long-term trend from 1999 corresponding to a deepening of the oxygen-deficient waters and warming. The implications of our results for understanding the OMZ dynamics off Peru are discussed.

\section{Material and methods}

\subsection{Study site and data}

The study site corresponds to a station off the coast of Callao (central Peru; $12^{\circ} 02^{\prime} \mathrm{S}, 77^{\circ} 29^{\prime} \mathrm{W}$; Fig. 1) located $20 \mathrm{~nm}$ from the coast with $145 \mathrm{~m}$ of water column depth. The station was visited by the Instituto del Mar del Peru (IMARPE) ship on a monthly or bimonthly basis between 1996 and 2011 to carry out vertical profiles of temperature, salinity, oxygen and nutrients (nitrate, nitrite, phosphate and silicate). Gaps 


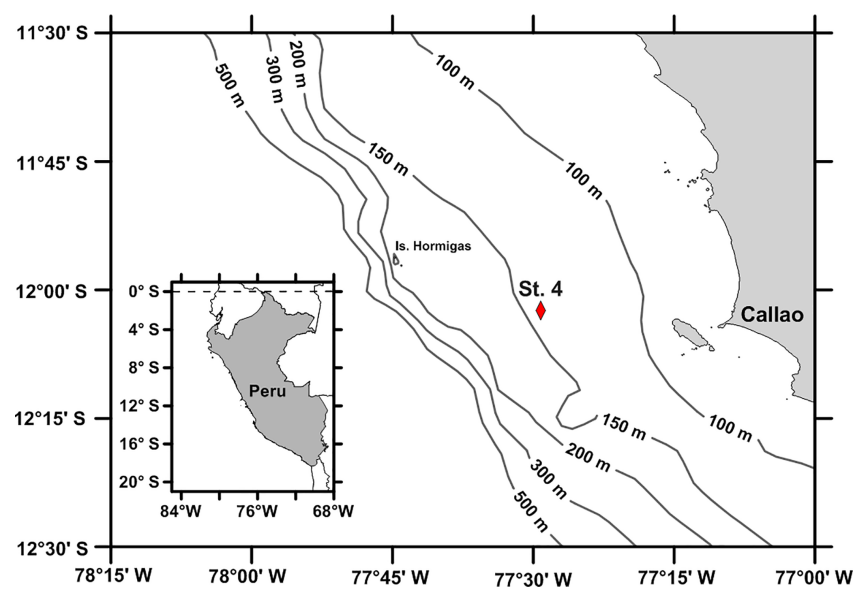

Figure 1. Location of the sampling station (St. 4; $20 \mathrm{~nm}, 145 \mathrm{~m}$ depth) in the coastal upwelling ecosystem off central Peru, Callao $\left(12^{\circ} 02^{\prime} \mathrm{S}, 77^{\circ} 29^{\prime} \mathrm{W}\right)$.

larger than 1 or 2 months are, however, present over this period with the year 2011 having $30 \%$ missing data, which results in some limitations and requires caution in processing the data and in interpreting the results (see Sect. 2.2).

The temperature was measured by an inversion thermometer through 2001 and by CTD (Sea-Bird SBE 19plus) from 2002. Salinity was measured by a salinometer through 2001 and by a CTD plus salinometer from 2002. Comparisons between CTD measurements and estimates of temperature and salinity derived from water samples from Niskin bottles were made regularly during all cruises to verify the proper calibration of the instruments.

Dissolved oxygen and nutrients were measured most of the time at standard depths $(0,10,30,50,75,100 \mathrm{~m})$. Dissolved oxygen was determined by a modified Winkler method (Grasshoff et al., 1999) with a precision of $0.5 \mu \mathrm{mol} \mathrm{kg}{ }^{-1}$. Nutrient samples (nitrate, nitrite, phosphate and silicate) were frozen and stored before being analyzed using standard colorimetric techniques (Parsons et al., 1984). The estimated accuracy of the method was $\pm 0.5 \mu \mathrm{mol} \mathrm{L}^{-1}$ for nitrate, $\pm 0.08 \mu \mathrm{mol} \mathrm{L}^{-1}$ for nitrite, $\pm 0.03 \mu \mathrm{mol} \mathrm{L}^{-1}$ for phosphate and $\pm 0.25 \mu \mathrm{mol} \mathrm{L}^{-1}$ for silicate. The fixed nitrogen deficit (Ndef) was determined by the following formula:

$\mathrm{Ndef}=12.6 \times\left[\mathrm{HPO}_{4}^{2-}\right]-\left(\left[\mathrm{NO}_{3}^{-}\right]+\left[\mathrm{NO}_{2}^{-}\right]\right)$.

The constant 12.6 is the empirically determined $\mathrm{N}: \mathrm{P}$ ratio of organic matter produced in these waters (Codispoti and Packard, 1980). Positive values indicate a nitrate deficit.

The OMZ was defined as the area with oxygen concentrations lower than $22.5 \mu \mathrm{mol} \mathrm{kg}{ }^{-1}$. This concentration was considered as the OMZ upper boundary (Schneider et al., 2006; Fuenzalida et al., 2009; Ulloa and Pantoja, 2009).

\subsection{Statistical analysis of time series}

The physical and chemical data off Callao showed missing monthly data, in particular for 2011 with up to $30 \%$ missing data. This is an inherent limitation of our data set that we have to take into account for the interpretation of the variability, particularly the intra-seasonal variability (periods ranging from 1 month to 3-4 months) associated with the aliasing induced by the sampling of the data (i.e., one data point at best per month). Since the environmental conditions in the study region vary at daily to intra-seasonal timescales (Dewitte et al., 2011), the approximation that one measurement yields a monthly mean data may be biassed. For this reason, the intra-seasonal variability in the data will not be documented in the paper, which will focus on seasonal and interannual timescales. As a consistency check and as an attempt to overcome such a limitation, we will use two methods to fill the gaps. First, the data were processed by linear interpolation in the vertical at each time step for which data are available. Then data are either linearly interpolated in the time domain (first method) or using a 6-month running mean filter (second method). At least two data points within the 6-month windows are required, which leads to a data set without gaps between January 1996 (data for 1995 are used to start in January 1996 using such a filtering) and September 2010. The latter procedure results in a low-pass filtering of the data so that aliasing and gridding artifacts are reduced compared to the first method. The first method is used to derive the oxycline and thermocline and second method is used to derive anomalies relative to a mean climatology. The latter is calculated from the raw data that have been only interpolated vertically at each time step on a regular grid (levels are 0,10 , $25,50,75$ and $100 \mathrm{~m}$ ). The period for the calculation of the climatology is 1999-2011 (i.e., 13 years), but due to the gaps in the time domain, each calendar month is calculated over a different number of years, always larger than 4 and lower than 12 . The anomalies were calculated as the difference between the low-pass filtered data and the mean climatology. Wavelet analyses are performed on the time series and the global wavelet spectrum is derived (Torrence and Compo, 1998).

Empirical orthogonal function (EOF) analysis (Thomson and Emery, 2014) was applied to the combined normalized time series of temperature, salinity, oxygen and inorganic nutrients to extract the statistically dominant mode of covariability between the different components of OMZ dynamics (i.e., physical versus biogeochemical). The normalization of the time series consists of dividing them by their standard deviation. The analysis was performed taking into account the time series at all depths between 5 and $100 \mathrm{~m}$ so that the statistics grasp some aspects of the vertical structure variability. The Pearson correlation coefficient $(r)$ was calculated between the data (or their PC time series) and some indices (see Sect. 2.3) and the significance level of the correlation was estimated based on the degree of freedom inferred from the 
Table 1. El Niño and La Niña years and their characteristics (magnitude and type).

\begin{tabular}{|c|c|c|}
\hline $\begin{array}{l}\text { El Niño (bold) } \\
\text { and La Niña } \\
\text { years }\end{array}$ & $\begin{array}{l}\text { Magnitude } \\
\text { (ONI) }\end{array}$ & $\begin{array}{l}\text { Type (eastern Pacific, EP, } \\
\text { versus central Pacific, CP) } \\
\text { (Yu and Kim, 2013) }\end{array}$ \\
\hline 1997-1998 & Strong (extraordinary) & $\mathrm{EP}$ \\
\hline 1998-1999 & Moderate & \\
\hline 1999-2000 & Moderate & \\
\hline $2000-2001$ & Weak & \\
\hline $2002-2003$ & Moderate & $\mathrm{CP}$ \\
\hline 2004-2005 & Moderate & $\mathrm{CP}$ \\
\hline 2006-2007 & Moderate & Mixed \\
\hline $2007-2008$ & Moderate & \\
\hline 2009-2010 & Moderate & $\mathrm{CP}$ \\
\hline 2010-2011 & Moderate & \\
\hline
\end{tabular}

autocorrelation of the time series (i.e., taking the lag when it reaches zero for the first time).

A long-term linear trend was calculated from the data that have been only interpolated vertically at each time step on the regular grid so that gaps in the time domain are considered in the estimate of the trend. They were calculated from January 1999 to avoid an artifact associated with the strong 1997-1998 El Niño event. We tested whether the value of the slope is significantly different from 0 based on a Student's $t$ test. If the significance level is lower than $80 \%$, the trend is considered not significant and only the slope values with a confidence level larger than $90 \%$ are discussed.

\subsection{El Niño indices and equatorial Kelvin waves (EKWs)}

In order to select the El Niño and La Niña years, we use the Oceanic Niño Index (ONI) provided by the National Oceanic and Atmospheric Administration, NOAA (NOAA CPC, 2015). The magnitude of the events (weak, moderate, strong) are based on the ONI, while the type of event (eastern Pacific (EP) versus central Pacific (CP) El Niño event) follows Yu and Kim (2013). This information is summarized in Table 1. To investigate the relationship between ENSO and the variability in the data, we use two other indices to account for the large-scale interannual variability in the equatorial Pacific. The two indices, named $E$ and $C$, were defined by Takahashi et al. (2011) and account respectively for the eastern Pacific El Niño events (hereafter EP events) and the central Pacific El Niño events (hereafter CP events). These two indices are obtained from the first two PC time series of the EOF modes of the SST anomalies in the tropical Pacific (HadISST data set; Rayner et al., 2003) over the period 1950-2014. Over the period of interest (1996-2011) the two indices are uncorrelated so that they can be conveniently used as a basis over which the variability in the data can be projected. The projection onto the $E$ index will account for the share of the variability in a particular field ( $T$, $S, \mathrm{O}_{2}$, nitrate or nitrite) that is associated with EP events, while the projection onto the $C$ index will quantify the relationship between $\mathrm{CP}$ events and the variability in the data. An approximate temperature (similarly for $S, \mathrm{O}_{2}$, nitrate and nitrite) field can therefore be derived through bilinear regression analysis: $T_{\text {approx }}(z, t)=<T(z, t) \mid E(t)>\cdot E(t)+<$ $T(z, t) \mid C(t)>\cdot C(t)$. It is expected that if there is a strong linear relationship with ENSO, the approximate data will explain a significant proportion or the variance in the original data. However this may not always be the case for two reasons: (1) the relationship between ENSO and the variability in the data is not necessarily linear. (2) The coastal data are influenced by timescales of variability that are not necessarily accounted for by the $E$ and $C$ indices since the latter are derived from SST, which is less variable than thermocline fluctuations (see Dewitte et al., 2008, for the equatorial region). In particular, Kelvin wave activity is enhanced several months prior to the ENSO peak (Mosquera-Vásquez et al., 2014) and the former can have a strong impact on coastal circulation (see Ramos et al., 2008, for the 1997-1998 El Niño event) although the ENSO peak is not already reached. That is why we will also use an estimate of the equatorial Kelvin wave (EKW) activity to account for aspects of the remote forcing not necessarily contained in the $E$ and $C$ indices.

The estimate of the EKW was derived from an ocean general circulation model (OGCM) simulation provided by Mercator, the European Institute for operational oceanography. The simulation has been validated from observations in a recent previous study (Mosquera-Vásquez et al., 2014), which indicates that, despite not assimilating observations, the simulation is as realistic as SODA oceanic reanalyses (Carton and Giese, 2008) in the near-equatorial region over their overlapping period (1992-2008). The use of an OGCM simulation to derive equatorial Kelvin waves is motivated by the possibility to estimate their vertical structure and separate waves with different propagating characteristics (phase speed and amplitude), which is not possible from observations. The method for deriving the wave coefficient consists of projecting the pressure and current anomalies from the model between $15^{\circ} \mathrm{S}$ and $15^{\circ} \mathrm{N}$ onto the theoretical vertical mode functions obtained from the vertical mode decomposition of the mean stratification. Kelvin wave amplitude is then obtained by projecting the results onto the horizontal modes at each grid point in longitude. The method has been shown to be successful in separating first and second baroclinic waves (Dewitte et al., 1999, 2008) that propagate at different phase speeds and impact the Peru coast in a very specific way (Illig et al., 2014). In particular, due to the sloping thermocline from west to east along the Equator, the second baroclinic mode Kelvin waves tend to be more energetic and influential on the upwelling variability off the Peruvian coast (Dewitte et al., 2011, 2012). For the correlation analysis with the dissolved oxygen data, we select the EKW amplitude $(\mathrm{cm})$ for the first and second baroclinic modes (hereafter EKW_1 and EKW_2) at $90^{\circ} \mathrm{W}$. Considering the phase speed of a coastal trapped Kelvin wave $\left(\sim 250 \mathrm{~km}^{\text {days }}{ }^{-1}\right)$, this can be assumed 
as a good proxy for what happens off Callao in terms of wave activity.

\section{Results}

\subsection{Temperature and salinity}

The evolution of temperature and salinity off Callao over 1996-2011 as a function of depth is shown in Fig. 2a and b. Temperature and salinity experience significant temporal fluctuations at a wide range of timescales. Fluctuations corresponding to near annual and interannual periods are observed in the thermocline depth $\left(15^{\circ} \mathrm{C}\right.$ isotherm). Several deepenings of the thermocline take place that correspond most of the time (but not always) to El Niño episodes and that are associated with enhanced salinity. There is a particularly strong deepening (more than $100 \mathrm{~m}$ ) of the $15^{\circ} \mathrm{C}$ isotherm between 1997 and 1998 associated with significantly saltier waters over the water column ( $>35.1$ ), which corresponds to the signature of the strong 1997-1998 El Niño event. Also note that the disappearance of the $15^{\circ} \mathrm{C}$ isotherm in the upper $100 \mathrm{~m}$ that took place in early 1997 (around April), well ahead of the El Niño peak phase (around November). A slight deepening of the thermocline also takes place at the beginning of 2002, 2005, 2010 and during winter of 2006, 2008, 2009 and 2011. This thermocline deepening was coincident with high salinity values clearly detected over the period 2002-2007.

The temperature data are further decomposed into a mean seasonal cycle and anomalies relative to this seasonal cycle (Fig. 3a and b). The latter is calculated over the period 1999-2011 in order to avoid a bias in the statistics due to the presence of the strong 1997-1998 El Niño. The mean seasonal cycle indicates that during austral winter and spring (June-August), colder conditions prevail in the water column, which is associated with lower saline conditions (34.835.1), particularly in the $17^{\circ} \mathrm{C}$ isotherm outcrops between July and November. Note that during winter a slight deepening of the thermocline takes place as evidenced by the evolution of the $15{ }^{\circ} \mathrm{C}$ isotherm, while during spring the thermocline is shallower (up to $20 \mathrm{~m}$ ). The climatology also reveals the existence of a semiannual component, which is thought to be related to the semiannual cycle of the equatorial variability through oceanic teleconnection (Ramos et al., 2006).

The temperature and oxygen anomalies (Fig. 3a) highlight the rich spectrum of variability and the differences between the strong 1997-1998 El Niño, an EP event and the subsequent periods. While temperature anomalies reach $\sim 5^{\circ} \mathrm{C}$ at all depths during the 1997-1998 EP El Niño event, they are much weaker $\left(\sim 1^{\circ} \mathrm{C}\right)$ for the following events and do not extend as deep. The period after 2000 corresponds to a period of dominant CP El Niño events that have a weaker amplitude than the 1997-1998 EP El Niño (Table 1), which explains the weaker temperature anomalies off Callao. A noticeable feature of the temperature anomalies after 1999 is also the existence of a long-term warming trend with a deepening of the $15^{\circ} \mathrm{C}$ isotherm estimated to $-0.30 \mathrm{~m} \mathrm{decade}^{-1}$. The analysis of the seasonality of the trend indicates that there is a long-term deepening of the thermocline in summer, spring and fall, while this is not the case in winter. The analysis of the trends (1999-2011) as a function of depth indicates that the warming takes place over the whole water column except at the surface (see Table 2).

\subsection{Dissolved oxygen}

The time series of dissolved oxygen over 1996-2011 off Callao exhibits a similar evolution as the thermohaline time series previously shown (Fig. 2c) with large fluctuations at interannual scales. The strong 1997-1998 El Niño event is associated with the largest and deepest oxygenation event over the entire record $\left(>100 \mu \mathrm{mol} \mathrm{kg}{ }^{-1}\right)$. A slight oxygenation in the water column takes place during 2002, 2006, 2008, 2009 and 2011. This oxygenation is evidenced in the position of the oxycline (iso-oxygen of $45 \mu \mathrm{mol} \mathrm{kg}^{-1}$ ) and OMZ upper boundary $\left(22.5 \mu \mathrm{mol} \mathrm{kg}{ }^{-1}\right.$ iso-oxygen $)$ depth. The climatology of dissolved oxygen (Fig. 3d) indicates a seasonal and semiannual component, since the oxycline and OMZ upper boundary depth is shallower in summer and early fall $(20-40 \mathrm{~m}$ ) and spring (up to $20 \mathrm{~m}$ ) and deeper in winter $(50 \mathrm{~m})$. Note that during summer, early fall and spring, oxygen-poor waters can intercept the euphotic layer and also the continental shelf, promoting suboxic and even anoxic conditions in bottom water underlying surface sediments $\left(\mathrm{O}_{2}\right.$ $<8.9 \mu \mathrm{mol} \mathrm{kg}^{-1}$; Fig. 2c).

The time series of dissolved oxygen anomalies (Fig. 3c) presents large positive oxygen anomalies during El Niño events, for example the intense oxygen anomaly $\left(>60 \mu \mathrm{mol} \mathrm{kg}^{-1}\right.$ ) associated with the strong 1997-1998 El Niño when well-oxygenated subtropical surface waters (SSWs) occupied the upper $100 \mathrm{~m}$ (Morón, 2000). The close relationship between the oxygen and thermocline depth during the 1997-1998 El Niño (i.e., positive $\mathrm{O}_{2}$ anomalies associated with a deepening of the thermocline) breaks down afterward for some events. Before 2000, the OMZ depth presents a significant correlation with the $15^{\circ} \mathrm{C}$ isotherm depth $(r=0.61, v-p<0.01)$. After 2000 , the correlation drops down $(r=0.28, v-p<0.01)$.

The position of the OMZ upper limit shows a negative trend after 1999 with a deepening estimated to $-0.64 \mathrm{~m} \mathrm{decade}^{-1}$ (see Table 2) that points to a long-term deepening of the oxygen-deficient waters similar to the deepening trend of the thermocline depth for the same period. No significant difference appears in the seasonality of the OMZ trend (Table 2), contrary to that of the thermocline $\left(15^{\circ} \mathrm{C}\right.$ depth) trend. The long-term trend (1999-2011) of oxygen concentration at different depths indicates a significant increase in oxygen in the entire water column. At the surface, the increase is $24.03 \mu \mathrm{mol} \mathrm{kg}^{-1}$ decade $^{-1}$ (Ta- 

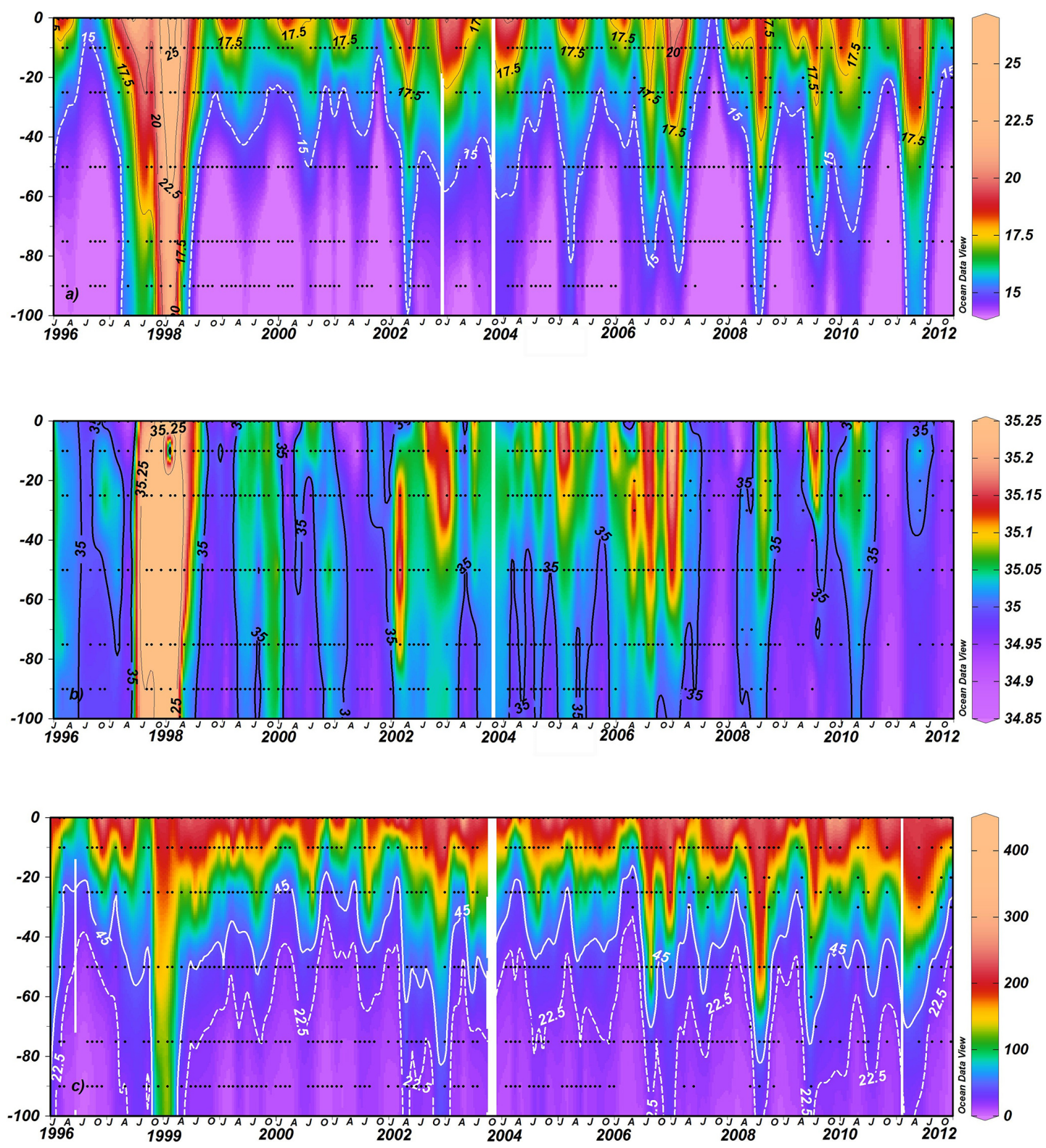

Figure 2. Time series of temperature $\left({ }^{\circ} \mathrm{C}\right)$ (a), salinity (b) and dissolved oxygen $\left(\mu \mathrm{mol} \mathrm{kg}{ }^{-1}\right)$ (c) during the 1996-2011 study years. Black dots indicate the location in space and time of the data, and a DIVA 2017 graphic interpolation was used for the visualization of the data.

ble 2), while the maximum trend is found in the first $25 \mathrm{~m}$ $\left(47.55 \mu \mathrm{mol} \mathrm{kg}{ }^{-1}\right.$ decade $\left.^{-1}\right)$.

\subsection{Nutrients and biogeochemical activity}

The time series of inorganic nutrient vertical distributions off Callao are shown in Fig. 4. Nitrate and nitrite concentrations ranged from ca. 0.0 to $27.0 \mu \mathrm{mol} \mathrm{L}^{-1}$ and ca. 0.2 to $9.0 \mu \mathrm{mol} \mathrm{L}^{-1}$, respectively. Lower nitrate values are present at the surface ( $5 \mathrm{~m}$ of depth) and in deep waters $(>80 \mathrm{~m}$ of depth), particularly during summer and fall periods, while maximum nitrite values appear in subsurface waters in contrast to the relationship with nitrate levels. During winter, high nitrate concentrations are found in the entire water column $\left(>15 \mu \mathrm{mol} \mathrm{L}^{-1}\right)$. The vertical distributions of silicate and phosphate exhibit a similar pattern as nitrate (not shown).

Nutrient data also present a strong interannual signal, particularly during the strong 1997-1998 El Niño event, with low nitrate concentrations $\left(<10 \mu \mathrm{mol} \mathrm{L}^{-1}\right)$ coincident with minimum and even zero nitrite values and low silicate and phosphate levels ( $<10$ and $1 \mu \mathrm{mol} \mathrm{L}{ }^{-1}$, respectively; Fig. 4). Between 1999 and 2001 nitrate concentrations were also lower than $10 \mu \mathrm{mol} \mathrm{L}^{-1}$ on average, but in contrast with the previous El Niño episodes, subsurface nitrite reached maxi- 


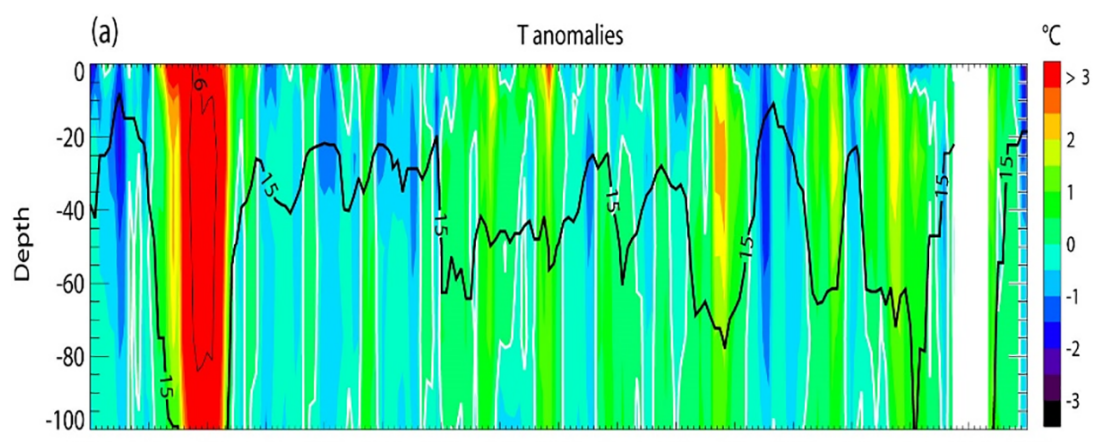

19961997199819992000200120022003200420052006200720082009201020112012

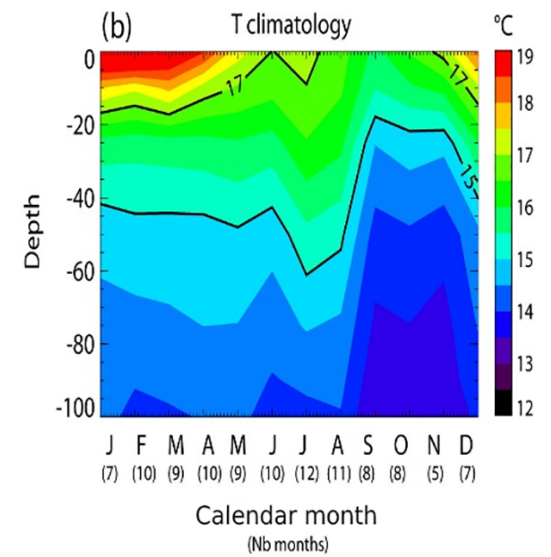

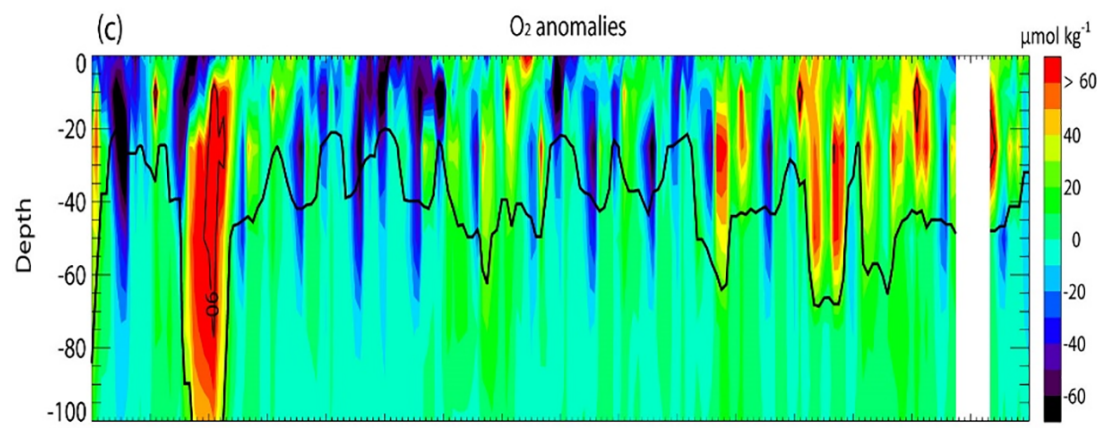

19961997199819992000200120022003200420052006200720082009201020112012

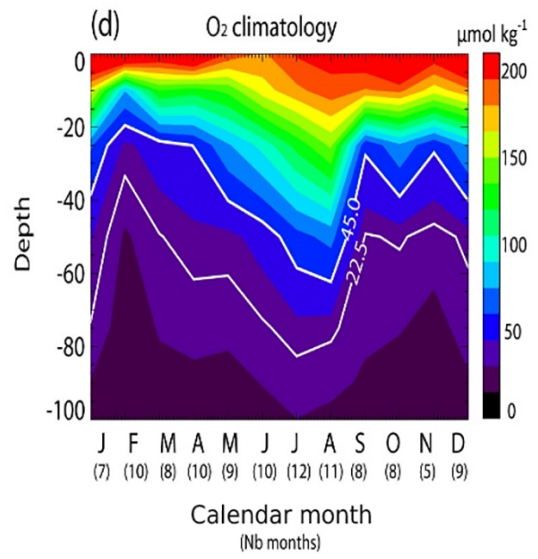

Figure 3. Temperature (top) and oxygen (bottom) anomalies relative to the mean climatology (a, c) and the respective climatologies (b, d). The $15{ }^{\circ} \mathrm{C}$ isotherm is indicated as a thick black line in panel (a). The $45 \mu \mathrm{mol} \mathrm{kg}^{-1}$ iso-contour for total oxygen concentration (oxycline) is overplotted in panel (c) as a thick black line, while the $90 \mu \mathrm{mol} \mathrm{kg}{ }^{-1}$ iso-contour for anomalies is drawn as a thin black line in order to visualize the amplitude of the anomalies during the 1997-1998 El Niño event. The number of years to derive the climatology is indicated in panels (b) and (d) below the calendar months.

Table 2. Slope of the linear fit for oxygen, temperature, salinity, nitrate and nitrite as a function of depth over the period 1999-2011. The slope for thermocline and oxycline depths are also provided as a function of season. The confidence level estimated based on a Student's $t$ test is indicated in parenthesis when larger than $80 \%$.

\begin{tabular}{|c|c|c|c|c|c|c|c|}
\hline $\begin{array}{l}\text { Depth } \\
\text { (meter) }\end{array}$ & \multicolumn{3}{|c|}{$\left(\mu \mathrm{mol} \mathrm{kg}{ }^{-1}\right.$ decade $\left.^{-1}\right)$} & $\begin{array}{r}T \\
\left({ }^{\circ} \mathrm{Cdecade}^{-1}\right)\end{array}$ & $\begin{array}{r}S \\
\left(\mathrm{PSU}_{\mathrm{decade}}{ }^{-1}\right)\end{array}$ & $\begin{array}{r}\text { Nitrate } \\
(\mu \mathrm{mol} \mathrm{L} \\
\left.-1 \text { decade }^{-1}\right)\end{array}$ & $\begin{array}{r}\text { Nitrite } \\
\left(\mu \mathrm{mol} \mathrm{L}{ }^{-1} \text { decade }^{-1}\right)\end{array}$ \\
\hline 0 & \multicolumn{3}{|c|}{$24.03(90 \%)$} & -0.04 & 0.026 & 0.93 & 0.11 \\
\hline 10 & \multicolumn{3}{|c|}{$47.55(95 \%)$} & $0.53(80 \%)$ & 0.013 & -0.17 & $-0.22(80 \%)$ \\
\hline 25 & \multicolumn{3}{|c|}{$40.35(95 \%)$} & $0.65(90 \%)$ & $0.025(80 \%)$ & -1.67 & -0.01 \\
\hline 50 & \multicolumn{3}{|c|}{$14.40(85 \%)$} & $0.50(90 \%)$ & 0.003 & 0.01 & -0.15 \\
\hline 75 & \multicolumn{3}{|c|}{$6.04(90 \%)$} & $0.34(90 \%)$ & -0.002 & 1.85 & -0.57 \\
\hline 90 & \multicolumn{3}{|c|}{$6.76(95 \%)$} & $0.42(95 \%)$ & -0.001 & $2.51(80 \%)$ & -0.75 \\
\hline 100 & \multicolumn{3}{|c|}{$7.53(95 \%)$} & $0.46(95 \%)$ & 0.003 & $2.95(80 \%)$ & -0.88 \\
\hline Annual & \multicolumn{2}{|c|}{$\begin{array}{r}\text { OMZ }\left(\text { m decade }^{-1}\right) \\
-0.64(95 \%)\end{array}$} & \multicolumn{2}{|c|}{$\begin{array}{r}\text { Thermocline }\left(\mathrm{m} \mathrm{decade}^{-1}\right) \\
-0.30(95 \%)\end{array}$} & & & \\
\hline \multirow[t]{2}{*}{ Seasonal } & $\begin{array}{r}\text { Summer } \\
-0.74(95 \%)\end{array}$ & $\begin{array}{r}\text { Winter } \\
-0.77(95 \%)\end{array}$ & $\begin{array}{r}\text { Summer } \\
-0.63(95 \%)\end{array}$ & $\begin{array}{r}\text { Winter } \\
0.03\end{array}$ & & & \\
\hline & $\begin{array}{r}\text { Fall } \\
-0.76(95 \%)\end{array}$ & $\begin{array}{r}\text { Spring } \\
-0.69(95 \%)\end{array}$ & $\begin{array}{r}\text { Fall } \\
-0.49(95 \%)\end{array}$ & $\begin{array}{r}\text { Spring } \\
-0.48(95 \%)\end{array}$ & & & \\
\hline
\end{tabular}



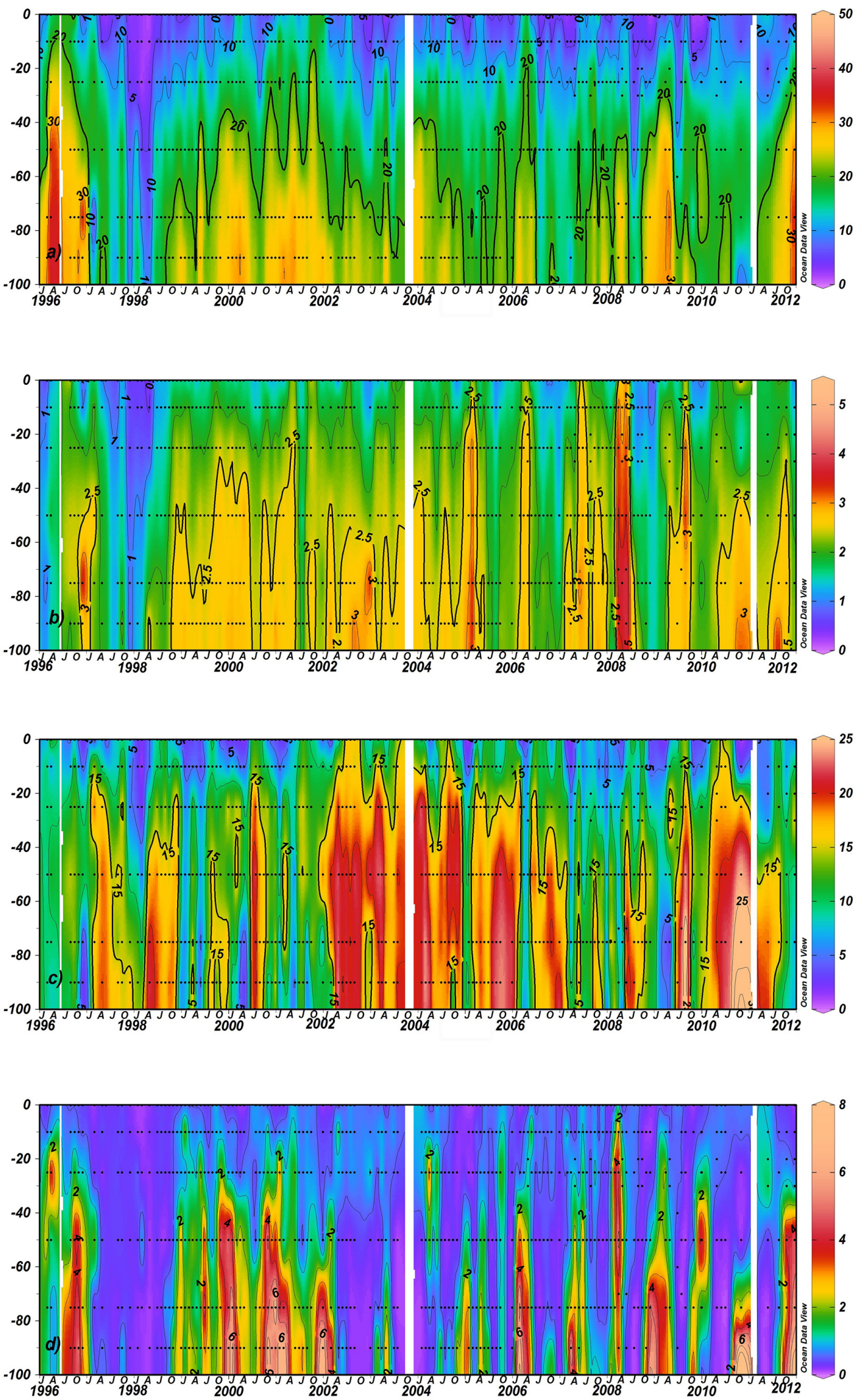

Figure 4. Time series of nitrate (a), nitrite (b), silicate (c) and phosphate (d) during 1996-2011. Units are $\mu \mathrm{mol} \mathrm{L} \mathrm{L}^{-1}$. Black dots represent the data, and the figure presents a DIVA 2017 graphic interpolation only for the visualization of the data. 


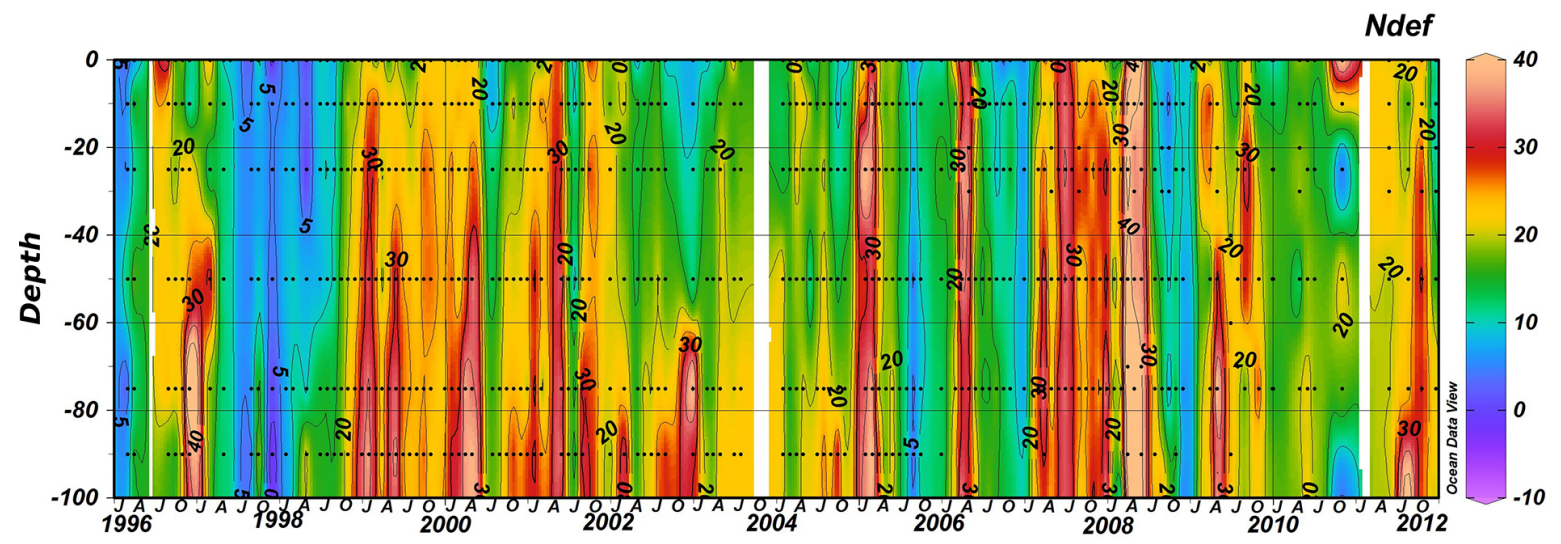

Figure 5. Time series of $\mathrm{N}$ deficit $\left(\mu \mathrm{mol} \mathrm{L}{ }^{-1}\right)$ at St. 4 off Callao during 1996-2011. Black dots represent the data, and the figure presents a DIVA 2017 graphic interpolation only for the visualization of the data.

mum values (up to $9 \mu \mathrm{mol} \mathrm{L} \mathrm{L}^{-1}$ ) coincident with intense OMZ development and a shallow thermocline (Fig. 2c).

Low silicate levels are registered at the sea surface, while silicate concentrations $>25 \mu \mathrm{mol} \mathrm{L}{ }^{-1}$ associated with phosphate concentrations $>3 \mu \mathrm{mol} \mathrm{L}-1$ are registered in subsurface waters. After 2000, subsurface nitrate concentrations reached the highest values $\left(>20 \mu \mathrm{mol} \mathrm{L}^{-1}\right)$ over the entire record coincident with lower nitrite and silicate concentrations (Fig. 4). High nitrite pools in the water column were described as a typical feature under oxygen-deficient waters (Deuser et al., 1978) and a tracer of denitrification (Codispoti and Packard, 1980; Codispoti and Christensen, 1985; Codispoti et al., 1986, 1988) and anammox activity (Hammersley et al., 2007; Lam et al., 2009; Lam and Kuypers, 2011) off Peru.

In order to explore biogeochemical activity related to the nitrogen cycle and the OMZ variability off Callao, Ndef in the water column is estimated (Fig. 5). Ndef values range from negative $\left(-5 \mu \mathrm{mol} \mathrm{L}^{-1}\right)$, which are indicative of low nitrate consumption, up to $40 \mu \mathrm{mol} \mathrm{L}^{-1}$, corresponding to conditions of high nitrate deficiency. Ndef exhibits a clear interannual signal with minimum values (zero-negative) during the 1997-1998 El Niño event coincident with welloxygenated waters (Fig. 2c). Low values of Ndef associated with almost zero nitrite concentrations suggest lower denitrification and/or anammox activity during these strong El Niño events. The significant effect on denitrification in the eastern South Pacific Ocean due to changes in the equatorial winds during El Niño was previously described by Codispoti et al. (1988). On the continental shelf off the coast of Callao, Dale et al. (2017) showed the occurrence of intraannual and interannual variability in the denitrification and anammox processes that appears to decrease under El Niño coupled with low primary productivity and high bottom water oxygenation. In contrast, between 1999 and 2001, Ndef of $40 \mu \mathrm{mol} \mathrm{L}{ }^{-1}$ peaked under a shallow and well-developed OMZ (Fig. 2c), pointing to nitrate reduction as an important route of organic matter remineralization, yielding high nitrate concentrations in subsurface waters (Fig. 4).

After 2000, Ndef water column conditions were highly variable coincident with the variability in the OMZ distribution and in general a less intense OMZ. Intense nitratedeficient conditions were registered in 2005, 2007 and at the end of 2011 coincident with La Niña conditions (Table 1). Ndef at the subsurface (50 and $90 \mathrm{~m}$ depth) was significantly correlated with the $15^{\circ} \mathrm{C}$ isotherm depth $(r=0.43$, $v-p<0.01)$ and with the $\mathrm{OMZ}$, though the correlation is relatively low $(r=0.28, v-p<0.01)$. The nitrate and nitrite data do not exhibit a significant long-term trend from 1999 over the water column (See Table 2) although the post2000 period has been characterized by a reduction (increase) in nitrite (nitrate).

\subsection{Equatorial forcing, Kelvin wave activity and the OMZ off central Peru}

As a first step, we document the linear relationship between the variability in the data and ENSO taking into accounts its diversity (i.e., the existence of EP and CP El Niño events). This consists of regressing the data onto the $E$ and $C$ indices, which yields approximate data that correspond to the results of a statistical model in which the $E$ and $C$ indices are predictors (see Sect. 2). The regression coefficients for the data are presented in Fig. 6 in a dimensionalized unit, which provides the range of variations in a given field during a strong EP El Niño event (red curves in Fig. 6) and during a CP El Niño event (blue curves in Fig. 6). Note that the $C$ index also accounts for the La Niña events so that the blue curves can be also interpreted as the variations of a particular field during a cold event. Figure 6 reveals that variations in temperature, salinity and oxygen during EP El Niño events are larger ( $\sim$ twice) than during CP El Niño events and of similar sign, consistent with the above description (Figs. 2 and 3). The variation as a function of depth is also rather 

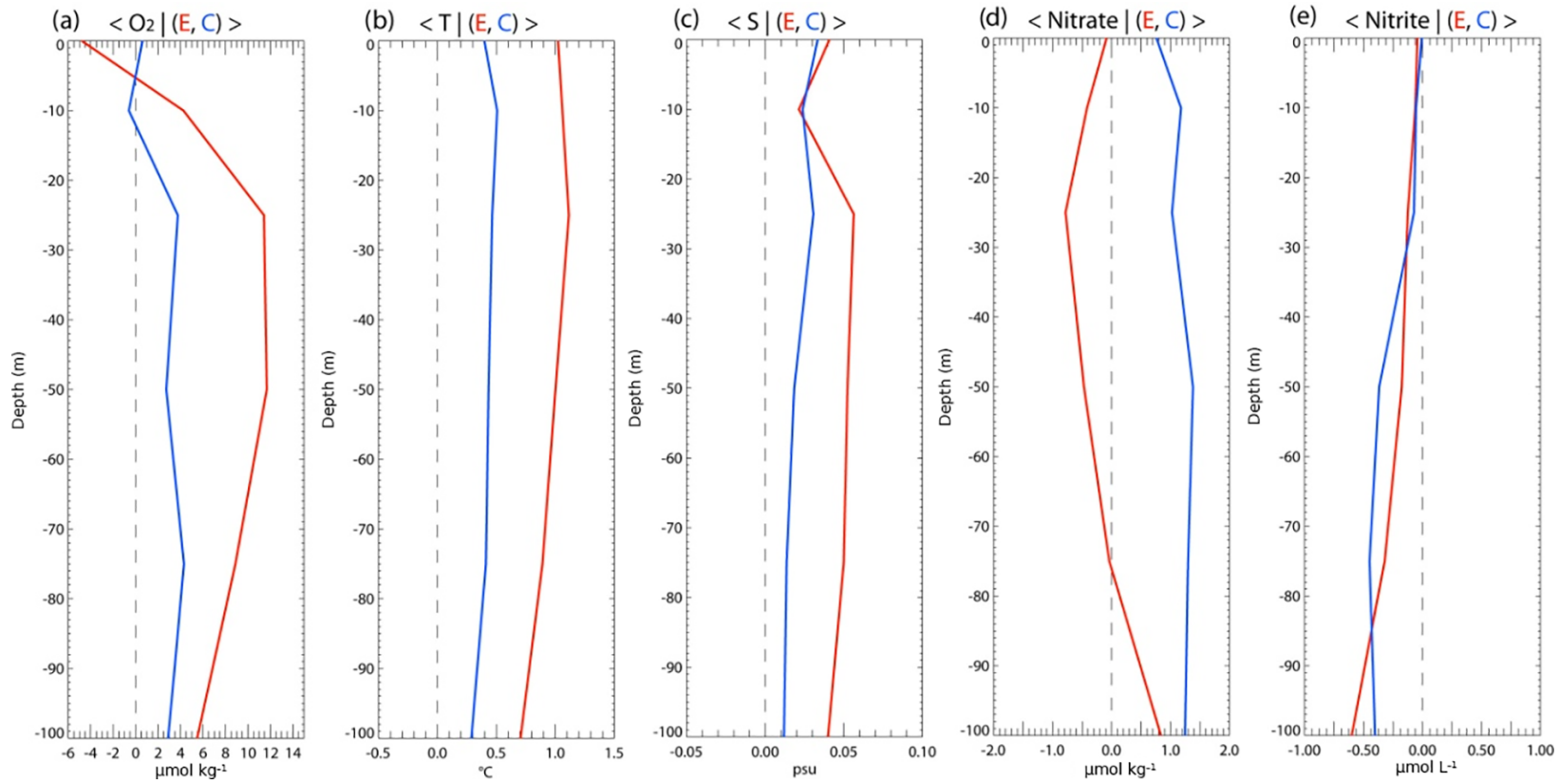

Figure 6. Projection of the data onto the (red line) $E$ and (blue line) $C$ indices for (a) oxygen, (b) temperature, (c) salinity, (d) nitrate and (e) nitrite.

homogeneous, except for oxygen in the upper layer. In contrast, the variations for nitrate tend to have opposite signs, and the amplitude during EP El Niño events is weaker in absolute value. The negative variation in nitrate during the EP El Niño events is consistent with the reduced upwelling during such events, which results in the deepening of the nutrient-rich cold coastal waters. In contrast, during CP El Niño events, nitrate concentration tends to increase consistently with the maintenance of upwelling conditions (see Dewitte et al., 2012). During both EP and CP El Niño events, nitrite tends to decrease with depth in a similar way that could be explained by oxygen availability under both El Niño types.

The relevance of these results needs to be assessed in light of the variance explained by the statistical model, which is provided in Fig. 7. The latter indicates a significant amount of variance explained by the linear statistical model for temperature and salinity $(\sim 30 \%)$. It is much less so for the biogeochemical fields, which could be for two reasons: (1) there is a significant contribution of nonlinear processes in the coupling between physics and biogeochemistry at ENSO timescales off Callao, and/or (2) the $E$ and $C$ indices do not account for all variability timescales relevant for the oceanic teleconnection off Peru onto the biogeochemistry (i.e., equatorial Kelvin wave). In order to gain further insight into the remote forcing of the $\mathrm{OMZ}$, we thus document the evolution of EKW activity during 1996-2011. The evolution of the amplitude of the EKW_1 and EKW_2 at $90^{\circ} \mathrm{W}$ in terms of sea level anomalies is shown in the Fig. 8a and b. These waves transmit their energy along the coast in the form of coastal trapped Kelvin waves and can trigger extratropical Rossby waves (Clarke and Shi, 1991). It is assumed that waves with amplitudes larger than 1 standard deviation over the study period are downwelling Kelvin waves, whereas amplitudes more negative than -1 standard deviation correspond to upwelling Kelvin waves. The EKW_2 activity is delayed by 1 month compared to EKW_1, consistent with the difference in the phase speed of the waves and their propagation from the central equatorial Pacific up to $90^{\circ} \mathrm{W}$. The maximum correlation between the two time series was before $2000(r=0.67, v-p<0.01)$ and was significantly lower after $2000(r=0.42, v-p<0.01)$.

Positive anomalies of EKW are associated with a deepening of $\mathrm{Z}_{-} 15^{\circ} \mathrm{C}(<0)$, as was observed during the strong 1997-1998 El Niño, the weak 2002-2003 El Niño and during 2006, 2008 and 2010 warm seasons. During these periods, EKW_1 and EKW_2 are almost in phase with comparable amplitude and Z_ $15^{\circ} \mathrm{C}$ and Z_OMZ (Fig. 8d) are out of phase. The EKW_1 and EKW_2 are highly correlated with $\mathrm{Z} \_15^{\circ} \mathrm{C}$ and $\mathrm{Z} \_\mathrm{OMZ}$ variables, but we find that EKW_2 has a stronger relationship with the $Z_{-} 15^{\circ} \mathrm{C}$ and $\mathrm{Z} \_\mathrm{OMZ}$ $(r-0.54,-0.40$ respectively; $v-p<0.01)$ than EKW_1 $(r-0.34,-0.23$ respectively; $v-p<0.01)$.

The global wavelet spectrum of the EKW_1 and EKW_2 time series at $90^{\circ} \mathrm{W}$ show that the second baroclinic mode is associated with lower frequency variability than the first baroclinic Kelvin wave mode (Fig. 8a, b). It is noteworthy that EKW_2 is negatively skewed since 2000 (normalized skewness $-0.8910 \mathrm{~cm}$ ) and there is a negative trend of upwelling events since 2000 (trend 


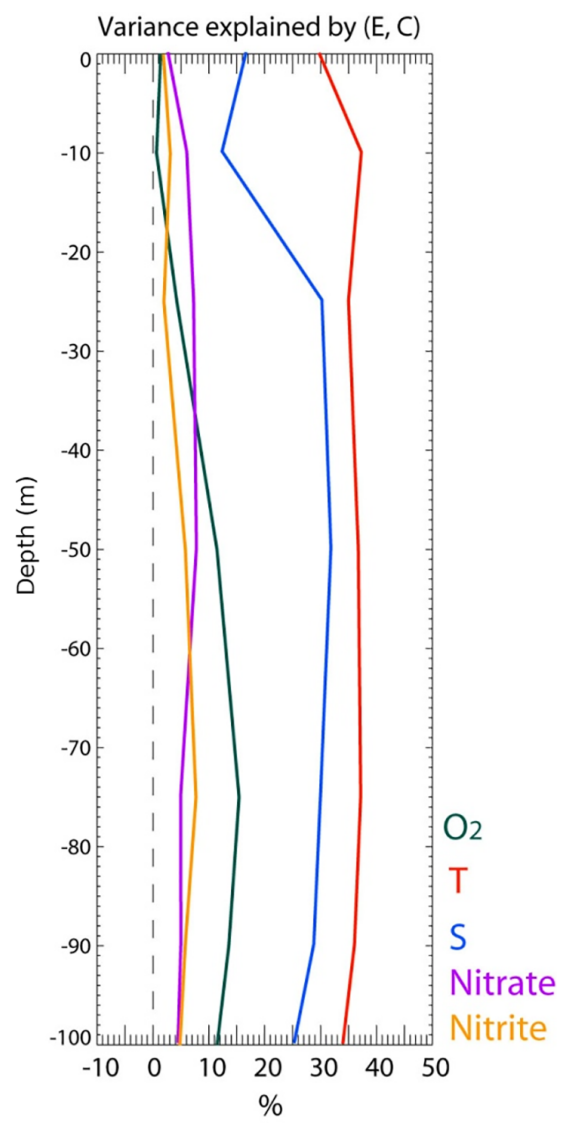

Figure 7. Percentage of variance explained by the projection of the data on the $E$ and $C$ modes as a function of depth for temperature (red), salinity (blue), oxygen (dark green), nitrate (purple) and nitrite (orange).

$\left.-0.0177 \mathrm{~cm} \mathrm{decade}^{-1}\right)$; these are features that are also encountered for $\mathrm{Z}_{-} 15^{\circ} \mathrm{C}$ (Fig. 8c) (normalized skewness $-1.330 \mathrm{~m}$, trend $\left.-0.30 \mathrm{~m} \mathrm{decade}^{-1}\right)$. The global wavelet spectra for $Z_{-} 15^{\circ} \mathrm{C}$ and Z_OMZ (Fig. 8h, i) also reveal a rich spectrum of variability that is characterized by a double peak, one at $\sim 4$ years and the other one near 2.2 years. Ndef at $50 \mathrm{~m}$ (Fig. 8d) exhibits a spectrum with a single dominant peak at $\sim 4$ years. To summarize, the spectral analysis of the synthetic proxies for the physical (EKW, Z_ $15^{\circ} \mathrm{C}$ ) and biogeochemical (Z_OMZ, Ndef at $50 \mathrm{~m}$ ) processes suggests that coupling between physics and biogeochemistry in relation to ENSO may take place at various timescales.

As an attempt to quantify such a coupling and its relationship with the remote forcing, an EOF analysis is performed combining all the data (temperature, salinity, oxygen, nitrate and nitrite; see Sect. 2 for details). The EOF analysis is performed over two periods, 1996-2010 and 19992010, to differentiate the coupling characteristics as a function of the El Niño types considering that the 1997-1998 EP El Niño event is very influential on the obtained statistics. The results of the EOF analysis are presented in Fig. 9 for the first and second EOF modes (EOF1 and EOF2). The PC time series for the period 1996-2010 indicate that the EOF1 mode mostly captures the variability $(43 \%)$ associated with the strong 1997-1998 El Niño event (with a high correlation between PC1 and the $E$ index; see Table 3), while the EOF2 mode explains $18 \%$ of the variance and does not relate to any particular events or series of events. The latter is confirmed by the low correlation between PC2 and the $E$ (or $C$ ) index (see Table 3). The EOF2 thus captures the share of the coupled variability that is not linearly related to the remote ENSO forcing, which is also supported by the low correlation between PC2 and the EKW time series (see Table 3). This is independent of the periods over which the EOF analysis is performed. For the 1999-2010 period the EOF analysis (Fig. 9d, e, f) indicates significant distinct characteristics from the EOF modes obtained for the entire period. In particular, the PC1 time series is highly correlated with the $C$ index when the EOF analysis is performed without including the 1997-1998 El Niño event, which indicates that the dominant EOF modes over the two periods capture the share of the coupled variability that is related to the different El Niño types. The patterns of EOF1 for the two periods (Fig. 9b, e) are comparable for temperature, salinity and oxygen; this indicates strong positive loading over most of the water column. Differences can be observed at the surface for oxygen where the loading of the EOF1 mode pattern over 1996-2010 is weaker near the surface compared to the period 1999-2010. This could be related to the strong warming of the mixed layer during the 1997-1998 El Niño event that leads to reduced solubility of oxygen and compensates for the downwelling-induced oxygenation. Differences in mode patterns between the two periods are more pronounced for nitrate and to a lesser extent for nitrite. In particular, the nitrate profile exhibits a bend near $30 \mathrm{~m}$ for the period 1996 2010 that is more marked than for the period 1999-2010. Differences in mode patterns between the two periods are emphasized for mode EOF2 (Fig. 9c, f), which is difficult to interpret. Note that the oxygen profiles have an opposite sign between the two periods, which suggests completely different coupled dynamics associated with the "natural" mode of variability. Overall the results of the EOF analysis suggest two different regimes of the coupling between physics and biogeochemistry over the two periods, which is associated with the El Niño types: a strong regime associated with the strong 1997-1998 EP El Niño event and a weak regime corresponding to the subsequent period during which the environmental forcing consists of the alternation of CP El Niño events and La Niña events and enhanced EKW activity. The coupling efficiency (i.e., strong versus weak) is provided by the amplitude of the mode patterns (Fig. 9b, e) and to some extent by the percentage of variance in EOF1, $43 \%$ for the period 1996-2010 and 37\% for the period 1999-2010.

The EOF analysis also indicates that the "forced" (i.e., by ENSO) coupled variability (EOF1) is related to ENSO through the forcing of the second baroclinic mode Kelvin 


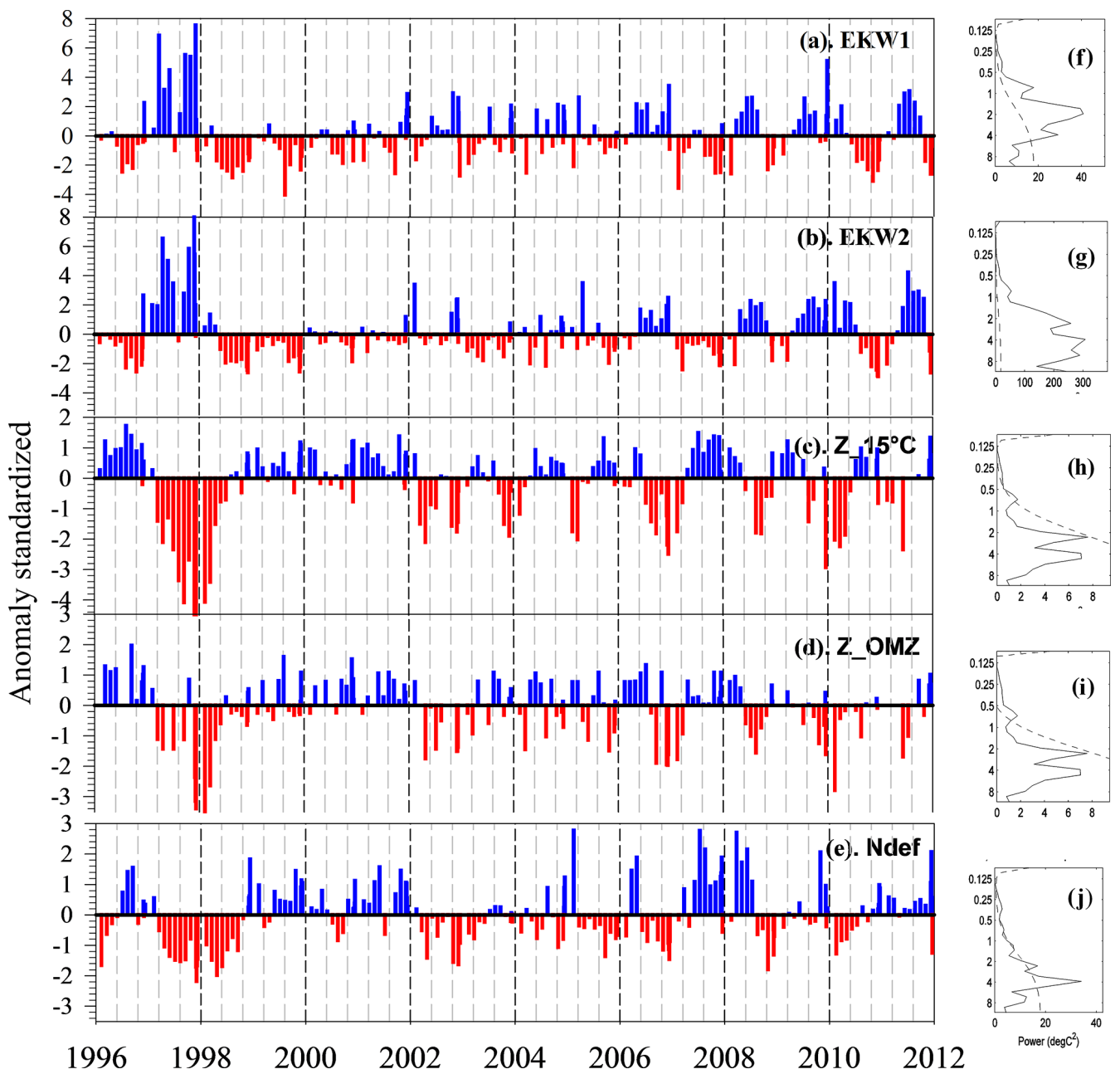

Figure 8. Evolution of the (a, b) amplitude of the equatorial Kelvin wave (EKW) anomalies at $90^{\circ}$ W for the first (EKW_1) and second (EKW_2) baroclinic modes. Units are cm (equivalent sea level). The standard deviation is indicated by the horizontal dashed lines. The time resolution of the data is every 5 days. (c) Depth of the thermocline, (d) OMZ upper boundary depth and (e) fixed nitrogen deficit (Ndef) at $50 \mathrm{~m}$ (f) at St. 4 off Callao during 1996-2011. On the right-hand side of each time series, the global wavelet spectra with a significance level at $95 \%$ are shown $(\mathbf{g}-\mathbf{j})$. The $95 \%$ confidence level is estimated from red noise (Markov model).

wave as evidenced by the large positive correlation between EKW_2 and PC1 for the two periods (Table 3). The EOF2 mode does not exhibit any linear relationship with ENSO and may account for the large natural variability in the coastal system and/or higher-frequency environmental forcing (e.g., internal waves, intra-seasonal variability from oceanic or atmospheric origin) that can rectify the circulation at interannual timescales. For instance, intra-seasonal Kelvin wave forcing may trigger changes in the circulation along the coast (Illig et al., 2014) that subsequently acts on the biogeochemistry through nonlinear dynamics (Vergara et al., 2016). Due to limitations in the data set, it is difficult to address this issue, which would require experimentation with a regional coupled model. This is beyond the scope of the present study.

\section{Discussion and concluding remarks}

The data for temperature, salinity, oxygen and nutrients between 1996 and 2011 in the central area of the Peruvian upwelling system reveal a rich spectrum of variability. The record encompasses one of the few strong equatorial Pacific (EP) El Niño events observed over the last 5 decades and the series of central Pacific (CP) El Niño events of the 2000s, which allows for the documentation of the OMZ dynamics under two different ENSO regimes and thus extends a previous study (Gutiérrez et al., 2008). Our analysis reveals two contrasting biogeochemical regimes associated with the two El Niño types. During the strong regime (strong 19971998 EP El Niño events), the biogeochemical properties are largely constrained by the wave-induced downwelling conditions reflected in extreme oxygenation, reduced nutrient availability and decreased nitrogen loss processes (denitri- 

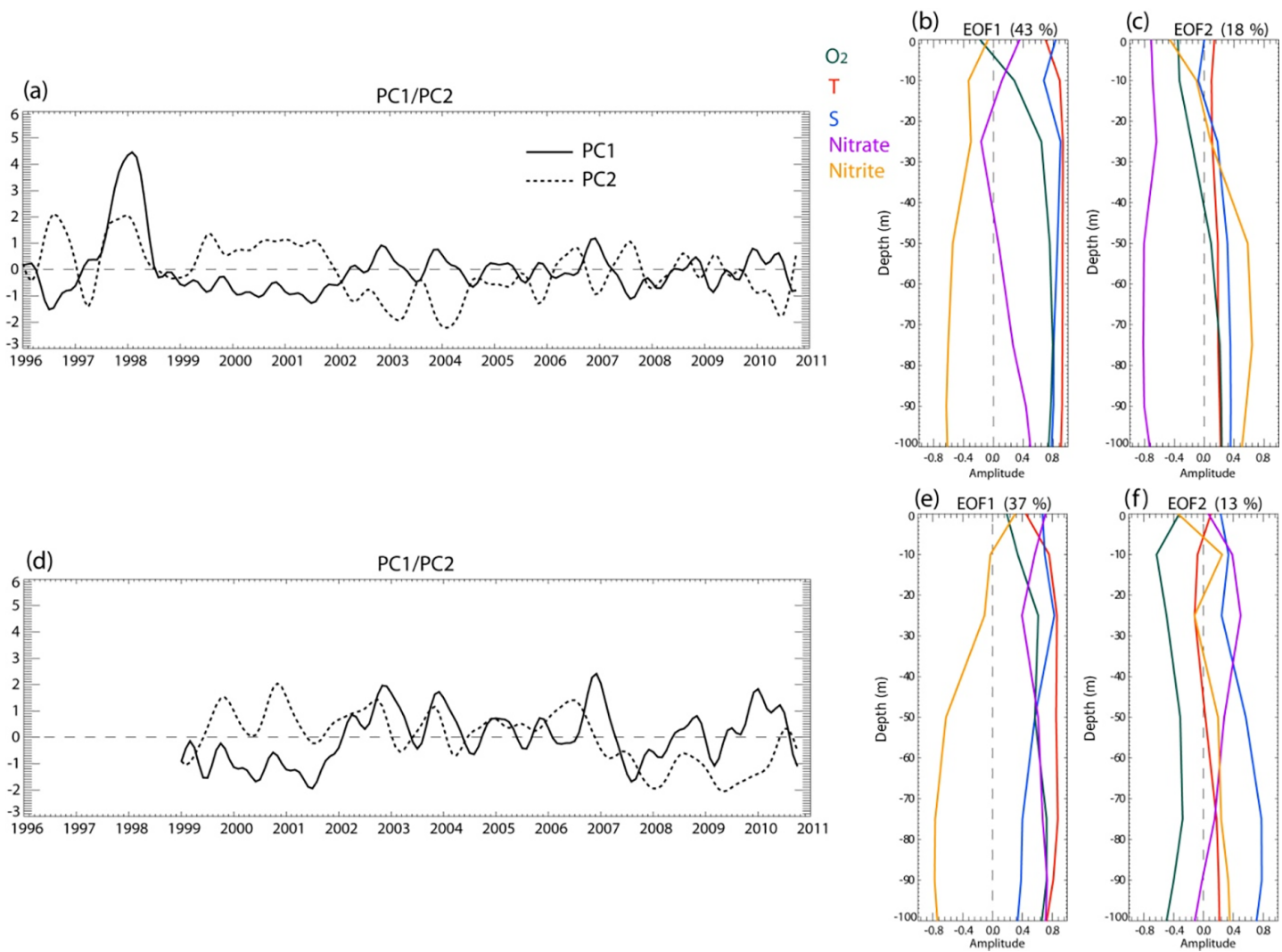

Figure 9. Combined EOF analysis of temperature, salinity, oxygen, nitrate and nitrite for the periods (top) 1995-2010 and (bottom) 19992010. (a, d) PC time series and (b, c, e, f) mode patterns for the first two EOF modes. A 6-month low-pass filter was applied to the data, and the data were normalized prior to carrying the EOF analysis so that the unit is dimensionalized.

Table 3. Correlation values between the PC time series, the ENSO indices $(E, C)$ and Kelvin wave amplitudes (EKW_1 and EKW_2) for the periods. Bold indicates the correlation values significant at the $95 \%$ level. $E$ is the eastern Pacific El Niño index) and $C$ is the central Pacific index as defined by Takahashi et al. (2011). Note that the $C$ index accounts for both central Pacific El Niño events and La Niña events.

\begin{tabular}{lrrrr}
\hline & $E$ & $C$ & EKW_1 & EKW_2 \\
\hline Period & \multicolumn{4}{c}{$1996-2010$} \\
\hline PC1 & $\mathbf{0 . 7 2}$ & 0.31 & 0.38 & $\mathbf{0 . 6 1}$ \\
PC2 & 0.28 & -0.27 & 0.00 & 0.07 \\
\hline Period & \multicolumn{4}{c}{$1999-2010$} \\
\hline PC1 & 0.23 & $\mathbf{0 . 5 8}$ & 0.33 & $\mathbf{0 . 5 3}$ \\
PC2 & -0.10 & 0.09 & 0.08 & -0.01 \\
\hline
\end{tabular}

fication, anammox). During the weak regime (CP El Niño events), less intense downwelling conditions determine a less intense OMZ (oxygen concentration increases weakly) and a higher nitrate concentration, and nitrogen loss processes appear not to be significant. Under the 1997-1998 EP El Niño, the biogeochemical activity was clearly coupled to the physical forcing, but this was not evident during the dominant $\mathrm{CP}$ El Niño regime. This reflects the distinct oceanic teleconnection through the equatorial Kelvin waves in which mean upwelling conditions are hardly altered during the CP El Niño events (Dewitte et al., 2012). The interpretation of the variability in these two regimes is consistent with the results of our EOF analysis combining physical and biogeochemical data (Fig. 9), which indicates that the statistics (explained variances of the modes and mode patterns) are modified regardless of whether or not the 1997-1998 El Niño event is considered in the analysis. In particular, whereas the dominant EOF mode that relates to the ENSO remote forcing explains less variance when the 1997-1998 El Niño is not considered in the analysis, the second EOF mode that is independent of ENSO exhibits a drastic change in the mode patterns for oxygen, nitrite and nitrate. This second mode can be interpreted as resulting from the natural variability in the coupled system, which is the variability associated with nonlinear processes in the biogeochemical system or the residual effect of other oceanic processes (e.g., eddy activity) on the mean circulation (i.e., rectification processes). The existence of natural variability in the OMZ is suggested by re- 
gional model simulations (Bettencourt et al., 2015; Vergara et al., 2016). Our results propose that such natural variability would be larger over periods when the frequency of CP El Niño events is larger than that of EP El Niño events.

The data set also offers the opportunity to explore longer timescales of variability. Our analysis in particular suggests a negative trend in oxygen concentration associated with a warming over the period 1999-2011. This is in contrast to the long-term deoxygenation trend over the last decades in the eastern tropical Pacific observed by Stramma et al. (2008, 2010). This suggests that either the low-frequency oxygen variability off Callao is not representative of the lowfrequency changes in the offshore $\mathrm{OMZ}$ or that the trend in our data is associated with decadal changes (since it is estimated over only 13 years). This would deserve further investigation in order to reconcile observations in the offshore ocean and at the coast of Peru. The other striking feature in our data set is that only temperature and oxygen experience a significant trend from 1999 (See Table 2). While the interpretation of the latter remains uncertain, it is consistent with the existence of a significant natural variability since trends could also emerge from nonlinear processes embedded into the biogeochemical coupled system. A better understanding of the natural variability would certainly benefit from experimentation with a regional coupled model, which needs to be taken into account for future work.

We now discuss some limitations of our analysis. First, our interpretation of OMZ variability does not consider aspects of wind forcing, although it is highly variable in the central Peru region and influential on upwelling dynamics. During El Niño events, there is a general weakening of the upwelling-favorable winds at a regional scale due to the relaxation of the southeastern branch of the trade winds, but near the coast winds can intensify locally because of underlying warm water effects (Dewitte and Takahashi, 2017). To what extent such anomalous winds influence the local oceanic circulation and associated biogeochemical response remains to be investigated. Considering the limited knowledge on this aspect and limitations in the wind data sets (Goubanova et al., 2011), we have not introduced the analysis of the local wind forcing at an interannual timescale here. However, this issue certainly deserves further investigation. Another important limitation of our study is associated with the sampling of the data. It may result in an aliasing of the high-frequency fluctuations embedded into the environmental forcing (i.e., intra-seasonal Kelvin wave and winds; Dewitte et al., 2011) into the low-frequency fluctuations and may bias the estimate of the low-frequency mode. A gridding procedure to fill gaps in the data can also introduce unrealistic timescales of variability. We have confronted two gridding procedures (one based on simple low-pass filtering and the other using a 6-month running mean filter), and they qualitatively lead to comparable results in terms of the interannual and long-term variability. It would be interesting to quantitatively assess the effect of the aliasing of high fre- quencies onto the monthly mean based on observations. The use of a long-term regional coupled model simulation would be also valuable for addressing this issue. Such a model could in particular allow for an investigation of the remote oceanic forcing associated with intra-seasonal Kelvin waves and the oxygen conditions off Peru, which was not possible from our data set. It could also help in better understanding how the intra-seasonal variability can rectify the interannual variability through nonlinear processes (e.g., eddy transport). Despite these limitations, the results presented in this paper are valuable as a benchmark for the validation of regional coupled models that aim to address the OMZ dynamics.

Overall, our results illustrate the rich spectrum of OMZ variability at interannual timescales, which cannot be solely interpreted as resulting from the ENSO oceanic teleconnection. Natural variability in the OMZ is expected from the complex of processes involved. Our analysis provides a first assessment of such variability from observations. Understanding the intensity and distribution of the OMZ is essential to understanding changes in nutriments and finally predicting the productivity and distribution of marine resources. The existence of the two regimes suggested here needs to be tested from global or regional models, which could provide a pathway for understanding the sensitivity of the OMZ to climate variability and lead to a better prediction of global change scenarios.

Data availability. The research data can be accessed by contacting the corresponding author. The Instituto del Mar del Peru agrees with international policies of transparency and we are working to enable direct data access in the short term.

Competing interests. The authors declare that they have no conflict of interest.

Acknowledgements. This research was supported by the Instituto del Mar del Peru (IMARPE). We thank Carlos Robles and Miguel Sarmiento, the technical chemical staff. Thanks to the crew of the IMARPE VIII and the SNP-2 research vessels and all the scientific colleagues who help us. This work is a contribution to the project "Integrated Study of the Upwelling system off Peru" developed by the first author in the Direction of Oceanography and Climate Change Research of IMARPE. Boris Dewitte acknowledges support from FONDECYT (projects 1151185 and 1171861). Mercator is thanked for providing the model data to derive the Kelvin wave estimate. We are grateful to the two anonymous reviewers for their constructive comments that helped to improve the paper. This work is a contribution to the project "Integrated Study of the Upwelling system off Peru" developed in the Direction of Oceanography and Climate Change Research of IMARPE.

Edited by: Gerhard Herndl

Reviewed by: Fabian Gomez and one anonymous referee 


\section{References}

Ashok, K., Behera, S. K., Rao, S. A., Weng, H., and Yamagata, T.: El Niño Modoki and its possible teleconnection, J. Geophys. Res., 112, C11007, https://doi.org/10.1029/2006JC003798, 2007.

Bertrand, A., Ballón, M., and Chaigneau, A.: Acoustic observation of living organisms reveals the upper limit of the oxygen minimum zone, PLoS ONE, 5, E10330, https://doi.org/10.1371/journal.pone.0010330, 2010.

Bettencourt J., Lopez, C., Hernandez-Garcia, E. Montes, I., Sudre, J., Dewitte, B., Paulmier, A., and Garçon, V.: Boundaries of the Oxygen Minimum Zone shaped by coherent mesoscale dynamics, Nat. Geosci., 8, 937-940, https://doi.org/10.1038/NGEO2570, 2015.

Calienes, R. and Guillén, O.: Masas de agua y producción primaria en el Perú, Bol. Inst. Mar Perú, Volume Extraordinario ICANE, 155-163, 1981.

Capotondi A., Wittenberg, A., Newman, M., Di Lorenzo, E., Yu, J.Y., Braconnot, P. Cole, J., Dewitte, B., Giese, B., Guilyardi, E., Jin, F.-F., Karnauskas, K., Kirtman, B., Lee, T., Schneider, N., Xue, Y., and Yeh, S.-W.: Understanding ENSO diversity, B. Am. Meteorol. Soc., 96, 921-938, https://doi.org/10.1175/BAMS-D13-00117.1, 2015.

Carton, J. A. and Giese, B. S.: A reanalysis of ocean climate using Simple Ocean Data Assimilation (SODA), Mon. Weather Rev., 136, 2999-3017, 2008.

Chavez, F. and Messié, M.: A comparative analysis of eastern boundary upwelling ecosytems, Prog. Oceanogr., 83, 80-96, 2009.

Chavez, F. P., Bertrand, A., Guevara-Carrasco, R., Soler, P., and Csirke, J.: The northern Humboldt Current System: brief history, present status and a view towards the future, Prog. Oceanogr., 79, 95-105, 2008.

Clarke, A. J.: The reflection of equatorial waves from oceanic boundaries, J. Phys. Oceanogr., 13, 1193-1207, 1983.

Clarke, A. J. and Shi, C.: Critical frequencies at ocean boundaries, J. Geophys. Res., 96, 10731-10738, https://doi.org/10.1029/91JC00933, 1991.

Clarke A. and van Gorder, S.: On ENSO coastal currents and sea level, J. Phys. Oceanogr., 24, 661-680, 1994.

Codispoti, L. A. and Christensen, J. P.: Nitrification, denitrification and nitrous oxide cycling in the eastern tropical South Pacific Ocean, Mar. Chem., 16, 277-300, 1985.

Codispoti, L. A. and Packard, T. T.: Denitrification rates in the eastern tropical South Pacific, J. Mar. Res., 38, 453-477, 1980.

Codispoti, L. A., Friederich, G., Packard, T. T., Glover, H. E., Kelly, P. J., Spinrad, R. W., Barber, R. T., Elkins, W., Ward, B. B., Lipschultz, F., and Lostanau, N.: High nitrite levels off northern Perú, A signal of instability in the marine denitrification rate, Science, 233, 1200-1202, 1986.

Codispoti, L. A., Friederich, G., Packard, T. T., and Barber, B. B.: Remotely driven thermocline oscillations and denitrification in the Eastern South Pacific: The potential for high denitrification rates during weak coastal upwelling, Sci. Total Environ., 75, 301-318, 1988

Criales-Hernández, M. I., Graco, M., Ayón, P., Flores, G., Schwamborn, R., Hirche, H.-J., and Wolff, M.: Temporal variability of the mesozooplankton community in the Humboldt upwelling system off central Peru, Extended Abstracts, Inter- national Conference The Humboldt Current System: Climate, ocean dynamics ecosystem processes and fisheries, Lima, 151 pp., 27 November-1 December 2006.

Dale, A. W., Graco, M., and Wallmann, K.: Strong and Dynamic Benthic-Pelagic Coupling and Feedbacks in a Coastal Upwelling System (Peruvian Shelf), Front. Mar. Sci., 4, 29 pp., https://doi.org/10.3389/fmars.2017.00029, 2017.

Deuser, W. G., Ross, E. H., and Mlodzinska, Z. J.: Evidence for and rate of denitrification in the Arabian Sea, Deep-Sea Res., 25, 431-445, 1978

Dewitte, B. and Takahashi, K.: Diversity of moderate El Niño events evolution: role of air-sea interactions in the eastern tropical $\mathrm{Pa}$ cific, Clim. Dynam., in revision, 2017.

Dewitte, B., Reverdin, G., and Maes, C.: Vertical structure of an OGCM simulation of the equatorial Pacific Ocean in 1985-1994, J. Phys. Oceanogr., 29, 1542-1570, 1999.

Dewitte, B., Purca, S., Illig, S., Renault, L., and Giese, B.: Low frequency modulation of the intra-seasonal equatorial Kelvin wave activity in the Pacific ocean from SODA: 1958-2001, J. Climate, 21, 6060-6069, 2008

Dewitte, B., Illig, S., Renault, L., Goubanova, K., Takahashi, K., Gushchina, D., Mosquera-Vásquez, K., and Purca, S.: Modes of covariability between sea surface temperature and wind stress intra-seasonal anomalies along the coast of Peru from satellite observations (2000-2008), J. Geophys. Res., 116, C04028, https://doi.org/10.1029/2010JC006495, 2011.

Dewitte, B., Vazquez-Cuervo, J., Goubanova, K., Illig, S., Takahashi, K., Cambon, G., Purca, S., Correa, D., Gutiérrez, D., Sifeddine, A., and Ortlieb, L.: Change in El Niño flavors over 1958-2008: Implications for the long-term trend of the upwelling off Peru, Deep-Sea Res. Pt. II, 77-80, 143-156, 2012.

Echevin, V., Aumont, O., Ledesma, J., and Flores, G.: The seasonal cycle of surface chlorophyll in the Peruvian upwelling system: A modeling study Prog. Oceanogr., 72, 167-168, 2008.

Ekau, W., Auel, H., Pörtner, H.-O., and Gilbert, D.: Impacts of hypoxia on the structure and processes in pelagic communities (zooplankton, macro-invertebrates and fish), Biogeosciences, 7, 1669-1699, https://doi.org/10.5194/bg-7-1669-2010, 2010.

Franz, J., Krahmann, G., Lavik, G., Grasse, P., Dittmar, T., and Riebesell, U.: Dynamics and stoichiometry of nutrients and phytoplankton in waters influenced by the oxygen minimum zone in the eastern tropical Pacific, Deep-Sea Res. Pt. I, 62, 20-31, 2012.

Friederich, G., Ledesma, J., Ulloa, O., and Chavez, F.: Air-sea carbon dioxide fluxes in the coastal southeastern tropical Pacific, Prog. Oceanogr., 72, 156-166, 2008.

Fuenzalida, R., Schneider, W., Garcés-Vargas, J., Bravo, L., and Lange, C.: Vertical and horizontal extension of the oxygen minimum zone in the eastern South Pacific Ocean, Deep Sea Res. Pt. II, 56, 1027-1038, 2009.

Furue, R., McCreary, J. P., Yu, Z., and Wang, D.: The dynamics of the southern Tsuchiya Jet, J. Phys. Oceanogr., 37, 531-553, 2007.

Goubanova, K., Echevin, V., Dewitte, B., Codron, F., Takahashi, K., Terray, P., Vrac, M.: Statistical downscaling of sea-surface wind over the Peru-Chile upwelling region: diagnosing the impact of climate change from the IPSL-CM4 model, Clim. Dynam., 36, 1365-1378, https://doi.org/10.1007/s00382-010-0824-0, 2011.

Graco, M. I., Ledesma, J., Flores, G., and Girón, M.: Nutrientes, oxígeno y procesos biogeoquímicos en el sistema de surgencias 
de la corriente de Humboldt frente a Perú, Rev. Biol. Peruana, 14, 117-128, 2007.

Grasshoff, K., Ehrhardt, M., Kremling, K., and Anderson, L. G.: Methods of seawater analysis, Wiley, 1999.

Guillén, O. and Izaguirre de Rondán, R.: Nutrients in the Perú coastal current, in: Oceanography of the South Pacific 1972, edited by: Fraser, R., National commission for UNESCO, 397418, 1973.

Guillén, O. G., Cárcamo, E. A., and Calienes, R.: Oxígeno disuelto, nutrientes y clorofila frente a la costa peruana durante el Niño 1987, Bol. Imarpe, Vol. Especial, 83-94, 1989.

Gutiérrez, D., Enríquez, E., Purca, S., Quipuzcóa, L., Marquina, R., Flores G., and Graco, M.: Oxygenation episodes on the continental shelf of central Peru: remote forcing and benthic ecosystem response, Prog. Oceanogr., 79, 177-189, 2008.

Gutiérrez, D., Bouloubassi, I., Sifeddine, A., Purca, S., Goubanova, K., Graco, M., Field, D., Mejanelle, L., Velazco, F., Lorre, A., Salvatteci, R., Quispe, D., Vargas, G. Dewitte, B., and Ortlieb, L.: Coastal cooling and increased productivity in the main upwelling zone off Peru since the mid-twentieth century, Geophys. Res. Lett., 38, L07603, https://doi.org/10.1029/2010GL046324, 2011.

Hammersley, M. R., Lavik, G., Woebken, D., Rattray, J. E., Lam, P., Hopmans, H., Sinninghe Damsté, J. S., Kruger, S., Graco, M., Gutiérrez D., and Kuypers, M.: Anaerobic ammonium oxidation contributes significantly to nitrogen loss from the Peruvian oxygen minimum zone, Limnol. Oceanogr., 52, 923-933, 2007.

Helly, J. J. and Levin, L. A.: Global distribution of naturally occurring marine hypoxia on continental margins, Deep-Sea Res. Pt. I, 51, 1159-1168, 2004.

Illig, S., Dewitte, B., Goubanova, K., Cambon, G., Boucharel, J., Monetti, F., Romero, C., Purca, S., and Flores, R.: Forcing mechanisms of intra-seasonal SST variability off Peru in 2000-2008: local versus remote forcings, J. Geophys. Res.-Oceans, 119, 3548-3573, 2014.

Kock, A., Arévalo-Martínez, D. L., Löscher, C. R., and Bange, H. W.: Extreme $\mathrm{N}_{2} \mathrm{O}$ accumulation in the coastal oxygen minimum zone off Peru, Biogeosciences, 13, 827-840, https://doi.org/10.5194/bg-13-827-2016, 2016.

Lam, P. and Kuypers, M.: Microbial Nitrogen Cycling Processes in Oxygen Minimum Zones, Annu. Rev. Mar. Sci., 3, 317-345, 2011.

Lam, P., Lavik, G., Jensen, M. M., van de Vossenburg, J., Schmid, M.C., Woebken, D., Gutiérrez, D., Aman, R., Jetten, M. S. M., and Kuypers, M.: Revising the nitrogen cycle in the Peruvian oxygen minimum zone, P. Natl. Acad. Sci. USA, 106, 47524757, 2009.

Ledesma, J., Tam, J., León, V., Flores, G., and Morón, O.: Caracterización de la Zona de Mínimo de Oxígeno (ZMO) frente a la costa peruana entre $3^{\circ} \mathrm{N}$ y $14^{\circ} \mathrm{S}, 1999-2009$, Bol. Inst. Mar Perú, 26, 49-57, 2011.

Lee, T. and McPhaden, M. J.: Increasing intensity of El Niño in the central-equatorial Pacific, Geophys. Res. Lett., 37, L14603, https://doi.org/10.1029/2010GL044007, 2010.

Levin, L., Gutiérrez, D., Rathburn, T., Neira, C., Sellanes, J., Muñoz, P., Gallardo, V., and Salamanca, M.: Benthic processes on the Peru margin: a transect across the oxygen minimum zone during the 1997-98 El Niño, Prog. Oceanogr., 53, 1-27, 2002.
Montes, I., Colas, F., Capet, X., and Schneider, W.: On the pathways of the equatorial subsurface currents in the eastern equatorial Pacific and their contributions to the Peru-Chile Undercurrent, J. Geophys. Res., 115, C09003, https://doi.org/10.1029/2009JC005710, 2010.

Morales, C. E., Hormazábal, S. E., and Blanco, J. L.: Inter-annual variability in the mesoscale distribution of the depth of the upper boundary of the oxygen minimum layer off northern Chile (1824S): Implications for the pelagic system and biogeochemical cycling, J. Mar. Res., 57, 909-932, 1999.

Morón, O.: Características del ambiente marino frente a la costa peruana, Bol. Inst. Mar Perú, 19, 179-204, 2000.

Morón, O. and Escudero, L.: Salinidad promedio de la superficie del mar frente a la costa peruana, Período 1928-1985, Internal Report, IMARPE, 1991.

Mosquera-Vásquez, K., Dewitte, B., and Illig, S.: The central Pacific El Niño intra-seasonal kelvin wave, J. Geophys. Res.-Oceans, 119, 6605-6621, https://doi.org/10.1002/2014JC010044, 2014.

NOAA CPC: Oceanic El Niño Index (ONI), available at: http://www.cpc.noaa.gov/products/analysis_monitoring/ ensostuff/ONI_v5.php, 2015.

Parsons, T. R., Maita, Y., and Lalli, C. M.: A manual of chemical and biological methods for seawater analysis, Pergamon Press, Oxford, UK, 173 pp., 1984.

Paulmier, A. and Ruiz-Pino, D.: Oxygen minimum zones in the modern ocean, Prog. Oceangr., 80, 113-128, 2009.

Pennington, J. T., Mahoney, K. L., Kuwahara, V. S., Kolber, D. D., Calienes, R., and Chavez, F.: Primary Production in the eastern tropical Pacific: a review, Prog. Oceanogr., 69, 285-317, 2006.

Ramos, M., Pizarro, O., Bravo, L., and Dewitte, B.: Seasonal variability of the permanent thermocline off northern Chile, Geophys. Res. Lett., 33, L09608, https://doi.org/10.1029/2006GL025882, 2006.

Ramos, M., Dewitte, B., Pizarro, O., and Garric, G.: vertical propagation of extratropical Rossby waves during the 1997-1998 El Niño of the west coast of South America in a medium resolution OGCM simulation, J. Geophys. Res., 113, C8041, https://doi.org/10.1029/2007JC004681, 2008.

Rayner, N. A., Parker, D. E., Horton, E. B., Folland, C. K., Alexander, L. V., Rowell, D. P., Kent, E. C., and Kaplan, A.: Global analyses of sea surface temperature, sea ice, and night marine air temperature since the late nineteenth century, J. Geophys. Res., 108, 4407, https://doi.org/10.1029/2002JD002670, 2003.

Rojas de Mendiola, B.: Seasonal phytoplankton distribution along the peruvian coast, in: Coastal Upwelling, edited by: Richards, F. A., American Geophysical Union, 348-356, 1981.

Sánchez, G., Calienes, R., and Zuta, S.: The 1997-1998 El Niño and its effect on the marine coastal system off Perú, CALCOFI reports, 41, 62-86, 1999.

Schneider, W., Fuenzalida, R., Garcés-Vargas, J., Bravo, L., and Lange, C.: Extensión vertical y horizontal de la zona de mínimo de oxígeno en el pacífico Sur oriental, Extended Abstract, The Oxygen Minimum Systems in the ocean: Distribution, Diversity and Dynamics Workshop, Concepción, Chile, 24-26 October, Suplemento Gayana, 70, 79-82, 2006.

Silva, N., Rojas, N., and Fedele, A.: Water masses in the Humboldt Current System: Properties, distribution, and the nitrate deficit as 
a chemical water mass tracer for Equatorial Subsurface Water off Chile, Deep-Sea Res. Pt. II, 56, 1004-1020, 2009.

Stramma, L., Johnson, G. C., Sprintall, J., and Mohrholz, V.: Expanding oxygen-minimum zones in the tropical oceans, Science, 320, 655-658, 2008.

Stramma, L., Schmidtko, S., Levin, L., and Johnson, G. C.: Ocean oxygen minima expansions and their biological impacts, DeepSea Res. Pt. I: Oceanographic Research Papers, 57, 587-595, 2010.

Strub, P. T., Mesías, J. M., Montecino, V., Rutlant, J., and Salinas, S.: Coastal ocean circulation off western South America, Coastal Segment (6, E), in: The Sea, edited by: Robinson, A. R. and Brink, K. H., Wiley, 273-313, 1998.

Takahashi, K., Montecinos, A., Goubanova, K., and Dewitte, B.: ENSO regimes: Reinterpreting the canonical and Modoki El Niño, Geophys. Res. Lett., 38, L10704, https://doi.org/10.1029/2011GL047364, 2011.

Thomson, R. E. and Emery, W. J.: Data analysis methods in physical oceanography, Third edition, Elsevier, 187-191, 425-536, 2014.

Torrence, C. and Compo, G. P.: A practical guide to wavelet analysis, B. Am. Meteorol. Soc., 79, 61-78, 1998.
Ulloa, O. and Pantoja, S.: The oxygen minimum zone of the eastern South Pacific, Deep-Sea Res. Pt. II, 56, 987-991, 2009.

Vergara, O., Dewitte, B., Montes, I., Garçon, V., Ramos, M., Paulmier, A., and Pizarro, O.: Seasonal variability of the oxygen minimum zone off Peru in a high-resolution regional coupled model, Biogeosciences, 13, 4389-4410, https://doi.org/10.5194/bg-134389-2016, 2016.

Wooster, W. S. and Gilmartin, M.: The Peru-Chile Undercurrent, J. Mar. Res., 19, 97-122, 1961.

Wyrtki, K.: The oxygen minima relation to ocean circulation, DeepSea Res., 9, 11-23, 1962.

Yeh, S.-W., Kug, J.-S., Dewitte, B., Kwon, M.-H., Kirtman, B. P., and Jin, F.-F.: El Niño in a changing climate, Nature, 461, 511515, 2009.

Yu, J. I. and Kim, S.-T.: Identifying the types of major El Niño events since 1870, Int. J. Climatol., 33, 2015-2112, 2013.

Zuta, S. and Guillén, O. G.: Oceanografía de las aguas costeras del Perú, Bol. Inst. Mar Perú, 2, 157-324, 1970. 